УДК 551.583:338.58:331.6:631

https://doi.org/10.47612/978-985-7149-55-1-2020-200-203

Николай Светлов, член-корреспондент Российской академии наук, доктор экономических наук, профессор, главный научный сотрудник ВИАПИ им. А. А. Никонова - филиал ФГБНУ ФНЦ ВНИИЭСХ, г. Москва, Россия

\title{
Влияние изменения климата на издержки обеспечения полной занятости в сельском хозяйстве России
}

Проблематика положительных внешних эффектов сельского хозяйства, их народнохозяйственной ценности, обретения ими статуса общественных благ [11] постоянно присутствует в исследовательской повестке экономистов-аграрников. В статье «Пять тезисов к оценке положительных экстерналий сельского хозяйства» нами обозначены и вынесены на обсуждение научной общественности логические рамки подхода к стоимостной оценке таких эффектов [6]. Суть пятого тезиса заключается в том, что их оценка требует принимать во внимание институциональный спрос на положительные внешние эффекты, а значит, выявлять готовность тех или иных институтов платить за них при обстоятельствах, когда они недоступны безвозмездно [9, с. 358]. Проведенное исследование обращается к одному из наиболее ценных положительных внешних эффектов сельского хозяйства, за который, в соответствии с пятым тезисом статьи [6], общество в лице своих демократических институтов готово было бы платить, если бы сельскохозяйственный бизнес не поставлял его даром, следуя своим коммерческим интересам, - это занятость сельского населения, его вовлеченность в трудовые отношения и обеспеченность стабильным источником дохода.

Исследование находится на стыке проблематики отыскания стоимостной меры внешних эффектов с одной из ключевых проблем аграрной политики России - хроническим отставанием доходов селян от городского населения и его опасным следствием - сельской бедностью. В январе 2019 г. министр сельского хозяйства Дмитрий Патрушев оценил долю сельского населения с доходами ниже прожиточного минимума в $20 \%$, сравнив ее с аналогичным показателем для городского населения - 11,2 \% [2]. Стратегический курс решения этой проблемы детально разработан [1], но когда речь идет о формировании смет соответствующих мероприятий, обоснование необходимости и достаточности выделенных финансовых ресурсов для решения поставленных задач пока еще не вполне обеспечено методическим инструментарием.

Приняв за основу положение, согласно которому полная занятость в сельском хозяйстве является внешним эффектом, обладающим ценностью в силу наличия институционального спроса на него, можно поставить следующий вопрос: какова величина издержек, которые понесет сельское хозяйство страны в случае обеспечения полной занятости трудовым ресурсам, которыми оно располагает - то есть работникам, фактически занятым в сельском хозяйстве, но рискующим потерять работу по мере роста производительности сельскохозяйственного труда, в том числе обусловленного глобальным потеплением, а также членам крестьянских хозяйств. Эта прибавка уже не будет иметь статус внешнего эффекта, так как не является побочным эффектом достижения иных целей - она требует от сельхозпроизводителей дополнительных затрат и потому трансформируется в общественное благо, производство которого должно быть им компенсировано теми институтами, которые заинтересованы в результате.

Поиск ответа на этот вопрос осложняется стремительными изменениями, происходящими в окружающей среде. Поэтому необходимо овладевать способами его решения применительно не только к текущей ситуации, но и к сценарным условиям, описывающим варианты вероятного будущего - в частности, варианты климатических условий, отличающиеся от существующих сегодня, и возможности адаптации к ним [4].

В данной статье, во-первых, излагается и демонстрируется на примере России методика оценки издержек поддержания полной занятости в сельском хозяйстве; во-вторых, объясняется, как применять инструментарий методики для оценки влияния изменения климата на эти издержки; в-третьих, даны конкретные оценки для определенных ниже сценарных условий. Выбранные сценарии не позиционируются здесь как наиболее вероятные: на данном этапе достаточно того, что они возможны. Впоследствии целесообразно получить аналогичные оценки для разнообразных климатических и демографических сценариев, обсуждаемых в научной литературе. Это позволит понять, какие различия между ними существенны с точки зрения поставленного вопроса.

Исследование выполнено при помощи модели частичного равновесия на рынках сельскохозяйственной продукции субъектов Российской Федерации [7], разработанной в ВИАПИ имени А. А. Никонова - филиале ФНЦ ВНИИЭСХ. В модель заложен новый принцип моделирования предложения, разработанный в ЦЭМИ РАН [5; 3, гл. 5]. Модель создавалась главным образом для приложений, связанных с исследованием последствий изменения климата и мер реагирования на них. В отличие от большинства других моделей частичного равновесия, она, благодаря инновационной $\mathrm{PF}+\mathrm{PE}-\mathrm{ap}-$ хитектуре, содержит в явной форме балансы ресурсов для сельскохозяйственного производства. Благодаря этому с ее помощью можно отражать климатические изменения на основе пространственного подхода (о чем подробнее сказано ниже), и эта же особенность делает возможным ее применение для решения задачи данного 
исследования. Становится возможным получить ответ на вопрос, которому посвящена статья, получив решения по сценариям, различающимся климатом и наличием либо отсутствием требования полного использования трудовых ресурсов.

Для целей данной статьи используется версия модели, в которой:

- в качестве базового использован период 20132017 гг. - границы производственных возможностей для каждого из пяти включенных в модель исходов случайных условий строятся по данным соответствующих лет этого периода;

- представлены 80 субъектов федерации (все, кроме входящих в состав других субъектов федерации, а также Республики Крым и Севастополя, данные по которым за базовый период не сопоставимы с данными по остальным регионам);

- моделируются производство, межрегиональные перевозки и внешняя торговля для пяти продуктов: пшеницы, зерна других видов (включая зернобобовые), семян подсолнечника, скота и птицы, молока;

- продажи остальной продукции сельского хозяйства учитываются в стоимостном выражении по месту производства;

объемы производства рассчитываются исходя из баланса труда, площади сельхозугодий, площади пашни, стоимости основных средств производства сельскохозяйственного назначения, поголовья скота и птицы в пересчете на крупный рогатый скот, энергетических мощностей, стоимости оборотных средств, баланса зернофуража;

- из перечисленных ресурсов стоимость основных средств, поголовье животных и энергетические мощности учитываются в модели по данным сельхозорганизаций, остальные ресурсы - в целом по сельскому хозяйству соответствующих субъектов федерации;

- применяются обновленные нормы потребления продовольствия, утвержденные Минздравом России в 2016 г.

Сценарий потепления, используемый в модели, основан на климатических прогнозах для России, полученных с помощью четырех различных GCM-моделей (моделей общей циркуляции атмосферы и океана) [10]. В деталях моделируемый сценарий описан в статье [12]. Модели других авторов, предназначенные для моделирования экономических последствий изменения климата, опираются на зависимость продуктивности от параметров климата - как правило, температуры и количества осадков. В данной модели используется более простой подход - пространственный. Суть его в том, что сценарий потепления отличается от базового сценария территорией, с которой связывается граница производственных возможностей, соответствующая той или иной природно-сельскохозяйственной зоне.

Для целей проводимого исследования требуются четыре сценария:

1) базовый, приближенный к факту, но предполагающий оптимальное использование имеющихся ресурсов (а значит, и более высокую производительность труда в сравнении с фактически достигнутой в базовом периоде) и дополненный требованием соответствия среднедушевого потребления продовольствия в каждом субъекте федерации нормам потребления продовольствия;

2) сценарий потепления, в котором условия базового сценария сочетаются с пространственной привязкой границ производственных возможностей для сценария потепления [12];

3) сценарий полного использования трудовых ресурсов, сохраняющий условия базового сценария и дополненный требованием полного задействования имеющихся ресурсов труда в сельскохозяйственном производстве в каждом субъекте федерации при любом из пяти исходов случайных условий, предусмотренных в модели;

4) сценарий полного использования трудовых ресурсов при потеплении, в котором условия третьего сценария сочетаются с условиями сценария [12].

Издержки сельского хозяйства, связанные с обеспечением полной занятости трудовых ресурсов, имеющихся в наличии в течение базового периода 2013-2017 гг., оцениваются для климатических условий данного периода как разница между суммарным маржинальным доходом сельского хозяйства страны при сценариях 1 и 2 ; для условий потепления - при сценариях 3 и 4. Влияние потепления на эти издержки определяется как разность в издержках сельского хозяйства, связанных с обеспечением полной занятости, в условиях потепления и при климате базового периода.

Следует подчеркнуть, что издержки, оцененные по такой методике, заведомо недостаточны для достижения полной занятости сельского населения. Речь идет только об издержках поддержания полной занятости работников сельского хозяйства и членов крестьянских хозяйств в условиях роста производительности сельскохозяйственного труда, которым сопровождается распространение лучших технологических практик из одних регионов страны в другие. Оценка издержек полной занятости на селе требует применения модели, охватывающей не только сельское хозяйство, но и все виды деятельности селян, приносящие им доход.

Результаты моделирования и расчетов по вышеописанной методике сведены в таблицу. Данные строки «маржинальный доход» рассчитываются как сумма шести значений, расположенных в таблице над соответствующей ячейкой этой строки.

Данные, представленные в таблице, показывают, что при существующих технологиях и при фактическом уровне обеспеченности остальными учтенными в модели ресурсами полное задействование всех имеющихся трудовых ресурсов во всех субъектах Российской Федерации при каждом из пяти учтенных в модели вариантов случайных условий сельскохозяйственного производства и сбыта продукции возможно ценой сокращения маржинального дохода сельского хозяйства России на 94,5 млрд руб. (здесь и далее речь идет о российских рублях, приведенных к среднегодовой стоимости российской национальной валюты в 2019 г.). Этот итог образован:

- сокращением выручки на внутренних рынках на 7,1 млрд руб. (0,12 \% к факту, причем цены падают 
Таблица. Расчет прироста издержек полной занятости, обусловленного изменением климата, млрд руб.

\begin{tabular}{|l|c|c|c|c|c|}
\hline \multirow{2}{*}{\multicolumn{1}{|c|}{ Показатели }} & \multirow{2}{*}{$\begin{array}{c}\text { Факт } \\
\text { (оценка) }\end{array}$} & \multicolumn{4}{|c|}{ Сценарий } \\
\cline { 4 - 6 } & & & \multicolumn{2}{|c|}{$\begin{array}{c}\text { позовый } \\
\text { потепление }\end{array}$} & $\begin{array}{c}\text { полная занятость } \\
\text { при потеплении }\end{array}$ \\
\hline Выручка на внутренних рынках & 5900,1 & 5761,4 & 5756,2 & 5754,2 & 5752,2 \\
\hline Учтенная экспортная выручка & 657,5 & 629,5 & 639,7 & 630,9 & 630,9 \\
\hline Стоимость учтенного импорта & $-1469,0$ & $-1385,7$ & $-1378,7$ & $-1447,0$ & $-1442,4$ \\
\hline Транспортные издержки & $-116,4$ & $-114,1$ & $-114,4$ & $-116,4$ & $-116,0$ \\
\hline Производственные издержки* & $-4372,5$ & $-4347,3$ & $-4336,8$ & $-4373,4$ & $-4370,2$ \\
\hline Остальные издержки & 0,0 & $-1,2$ & $-1,5$ & $-0,2$ & $-0,2$ \\
\hline Маржинальный доход & 599,8 & 542,6 & 564,5 & 448,1 & 454,1 \\
\hline Издержки полной занятости & - & - & - & $-94,5$ & $-110,4$ \\
\hline $\begin{array}{l}\text { Прирост издержек полной занятости из-за } \\
\text { изменения климата }\end{array}$ & - & - & - & - & $-15,9$ \\
\hline
\end{tabular}

Примечания. 1. Положительные значения в таблице соответствуют притокам, а отрицательные - оттокам денежных средств.

2. Таблица составлена по расчетам автора на основе сценарного моделирования.

* Без учета амортизации.

на $1,3 \%$, а физический объем поставок возрастает на $0,8 \%)$;

• ростом производственных издержек на 26,1 млрд руб. из-за того, что размещение производства теперь определяется не сравнительными конкурентными преимуществами природно-сельскохозяйственных зон и отдельных субъектов федерации с учетом их территориального положения по отношению к рынкам сбыта, а прежде всего наличием на селе трудовых ресурсов, которым нужно найти работу;

- ростом транспортных издержек на 2,2 млрд руб. по той же причине;

- ростом затрат на приобретение импортной продукции сельского хозяйства (в натуральном виде или в составе переработанной продукции) на 61,3 млрд руб.

В противовес перечисленным выше факторам действуют рост экспортной выручки на 1,3 млрд руб. и сокращение затрат на обслуживание краткосрочных кредитов на 1,0 млрд руб. Оба эти фактора имеют второстепенное значение.

В сценарии потепления маржинальный доход сельского хозяйства России выше, чем в базовом: разница составляет 21,9 млрд руб. Она достигается благодаря опережающему росту производительности труда при потеплении климата, что приводит к дальнейшему высвобождению рабочей силы. Занять ее всю - непростая задача, поэтому прибавка к маржинальному доходу в условиях полной занятости, обусловленная потеплением, меныше, чем аналогичная прибавка в условиях свободного рынка труда: она составляет всего 6,0 млрд руб., то есть 27,5 \% от прибавки в условиях, когда проблема относительного избытка труда в сельском хозяйстве остается нерешенной.

Как следствие, издержки обеспечения полной занятости в условиях потепления составят 110,4 млрд руб. - больше, чем при фактическом климате. Они образованы:

- сокращением выручки на внутренних рынках на 4,0 млрд руб. при несущественном (в среднем по стране) изменении цен на этих рынках под влиянием исполнения требования полной занятости трудовых ресурсов (рост на 0,2\%);

- падением экспортной выручки на 8,9 млрд руб.;

- ростом расходов на ввозимую продукцию сельского хозяйства на 63,7 млрд руб.;
- ростом пройзводственных издержек на 33,5 млрд руб.; - ростом транспортных издержек на 1,6 млрд руб.

Расходы на обслуживание краткосрочных кредитов при этом сокращаются на 1,3 млрд руб.

В итоге глобальное потепление удорожает решение проблемы полной занятости имеющихся (по состоянию на базовый период) работников сельского хозяйства и членов семей крестьянских хозяйств на 15,9 млрд руб.

В методическом плане главный результат проведенного исследования - разработанная методика оценки издержек полной занятости трудовых ресурсов сельского хозяйства в условиях роста производительности сельскохозяйственного труда и изменения климата. Сугь методики - в использовании возможностей модели частичного равновесия на рынках сельскохозяйственной продукции субъектов Российской Федерации для моделирования сценариев полной и неполной загруженности имеющихся трудовых ресурсов при фактических и сценарных климатических условиях.

Полученный результат дополняет существующие научные представления о способах оценки внешних эффектов сельского хозяйства и влияния сторонних факторов, в частности потепления, на эти эффекты. В этом отношении он способен повлиять на развитие подходов к оценке других внешних эффектов, найти возможности применения моделей частичного равновесия, основанных на PF+PE-архитектуре, для продвижения в создании соответствующих методик.

В практическом плане ценность имеют полученные количественные оценки таких издержек и доказательство того факта, что глобальное потепление, если оно пройдет по сценарию, заложенному в модель, их увеличит. Рост производительности труда, вызываемый той причиной, что благоприятные эффекты глобального потепления на значительной части территории России несколько превосходят его отрицательные последствия, обостряет проблему сбыта продукции в условиях полной загрузки этих трудовых ресурсов. Причина заключается в том, что достигаемый в этих условиях прирост производительности труда все еще недостаточно велик для того, чтобы уверенно и в крупных масштабах вытеснять продукцию зарубежных сельхозпроизводителей как с внутренних, так и с зарубежных рынков. 
При таких условиях обеспечение фронта работ для всех имеющихся трудовых ресурсов оказывается убыточным мероприятием для сельского хозяйства и может быть осуществлено только при наличии платежеспособного институционального спроса. Такой спрос в существующих ныне условиях может предъявить только государственная власть, распоряжающаяся средствами налогоплательщиков. Отрицательным результатом господдержки станет некоторое падение производительности труда в сравнении с потенциально достижимой, а значит, не будут созданы предпосылки преодоления зависимости занятости от господдержки.

По этой причине речь не должна идти о простой компенсации потерь сельхозтоваропроизводителей от задействования в производстве избыточных трудовых ресурсов. Рассчитанные значения - 94,5 млрд руб. в условиях фактического климата и 110,4 млрд руб. в условиях, описываемых заложенным в модель сценарием потепления - следует рассматривать как верхнюю границу (в пересчете на год) допустимых расходов из всех источников, направленных на такие решения задачи обеспечения полной занятости работников сельского хозяйства и семей, ведущих крестьянское хозяйство, которые бы не сдерживали рост производительности труда. Речь идет об отыскании мер структурной политики, направленных, вопервых, на исправление структурных диспропорций в обеспеченности субъектов федерации ресурсами сельскохозяйственного производства помимо трудовых, а во-вторых (и это главное), на расширение спектра имеющихся в их распоряжении технологических возможностей сельскохозяйственного производства за счет инноваций.

Обязательное требование к таким мерам - международная конкурентоспособность получаемой прибавки продукции, так как потенциал внутренних рынков ее сбыта практически исчерпан [8, с. 6]. Если в рамках существующей структуры ресурсного потенциала и ныне доступных технологий проблема сохранения рабочих мест в сельском хозяйстве может быть решена ценой не меньших издержек, чем рассчитанные выше, то среди решений структурно-инвестиционного характера могут найтись менее затратные - именно им и следует давать ход.

Отыскание конкретных решений такого рода - задача не государственной власти и не научных исследований, а предпринимателя, знающего местную специфику, рынки сбыта, владеющего данными о самых современных технологических решениях и о состоянии научно-технических разработок, относящихся к избранной им отрасли сельского хозяйства. Роль государства, заинтересованного в решении проблемы дефицита рабочих мест на селе, заключается в том, чтобы, во-первых, гарантировать выдачу грантов на проекты, направленные на рост занятости. Совокупный бюджет таких грантов не должен превосходить вышеуказанных издержек на достижение полной занятости, рассчитанных в предположении отсутствия структурных изменений. Во-вторых, от государства ожидается поддержка сбыта продукции: за рубеж - через прямое участие в развитии товаропроводящей инфраструктуры и в создании условий для формирования крупных конкурентоспособных товарных партий необходимого качества; на внутренних рынках - через адресную поддержку тех слоев населения, которые в силу своей низкой платежеспособности все еще не в состоянии приобретать рацион питания, соответствующий медицинским нормам.

\section{Список использованных источников}

1. Бондаренко, Л. В. Концептуальные основы региональной политики социального развития сельских территорий и программно-целевой подход к ее реализации / Л. В. Бондаренко // Экономика сельского хозяйства России. - 2019. - № 7. - С. 60-68.

2. Кузьмин, В. В селах создадут территории роста [Электронный ресурс] / В. Кузьмин // Российская газ. 2019. - 30 янв. - Режим доступа: https://rg.ru/2019/01/30/ minselhoz-razrabotaet-gosprogrammu-razvitiia-sel-k-15marta.html.- Дата доступа: 01.09.2020.

3. Применение математических методов в управлении АПК Беларуси и России / под ред. Н. М. Светлова, В. И. Буць. - М. : ЦЭМИ РАН, 2020. - 177 с.

4. Романенко, И. А. Адаптация региональных агропродовольственных систем к долгосрочным климатическим изменениям / И. А. Романенко, С. О. Сиптиц, Н. Е. Евдокимова. - М. : Аналитик, 2019. - 208 с.

5. Светлов, Н. М. Непараметрическая граница производственных возможностей в вычислимой модели частичного равновесия / Н. М. Светлов // Экономика и математические методы. - 2019. - № 4. - С. 104-116.

6. Светлов, Н. М. Пять тезисов к оценке положительных экстерналий сельского хозяйства / Н. М. Светлов // От роста к качеству роста в агропромышленном комплексе: как обеспечить переход? Второй Московский академический экономический форум 2020. Пленарная конференция. - М. : ВИАПИ им. А. А. Никонова, 2020.-С. 117-121.

7. Светлов, Н. М. Инновационная модель частичного равновесия в приложении к анализу эффектов изменения климата / Н. М. Светлов, Е. А. Шишкина// Междунар. сельскохозяйственный журн. - 2019. - № 5. - С. 58-63.

8. Шагайда, Н. И. Тенденции развития и основные вызовы аграрного сектора России : аналит. докл. / Н. И. Шагайда, В. Я. Узун; Центр стратегических разработок ; РАНХиГС. - М., 2017. - 88 с.

9. Economics of Ecosystem Services / A. Caparrós [et al.] // Mediterranean Oak Woodland Working Landscapes / P. Campos [et al.] (eds.) ; Landscape Series 16. Springer Science+Business Media Dordrecht, 2013. - P. 353-388.

10. Russia's Food Security and Climate Change: Looking into the Future/S. Kiselev [et al.] // Economics: The Open-Access, OpenAssessment E-Journal. -2013. Vol. 7. - Article 2013-39.

11. McVittie, A. A review of literature on the value of public goods from agriculture and the production impacts of the single farm payment scheme: Report RERAD/004/09/ A. McVittie, D. Moran, S. Thomson. - SAC Land Economy and Environment Research Group, 2009.

12. The effect of climate change on the location of branches of agriculture in Russia / N. Svetlov [et al.] // Studies on Russian economic development. - 2019. -№ 4. P. 406-418.

Материал поступил 01.10.2020 г. 